\title{
Modelo das 5 forças de porter adaptadas ao gestão pública
}

\section{Porter's 5 forces model adapted to public management}

DOI: $10.54018 /$ sssrv3n1-007

Recebimento dos originais: 01/01/2022

Aceitação para publicação: 02/02/2022

\author{
Nilson José de Oliveira Junior \\ Doutor em Administração pela USP - Universidade de São Paulo; Docente da \\ Universidade do Estado do Amazonas \\ E-mail: njoliveira@uea.edu.br
}

\section{RESUMO}

Este artigo teve como objetivo propor uma adaptação da ferramenta das 5 Forças de Porter para ser usada na análise do ambiente externo de uma organização pública e propor linhas de ações que visem superar os desafios estratégicos identificados. Para a realização do estudo foi realizada a compilação de trabalhos realizados com alunos de Pós-graduação em Gestão Pública da Universidade do Estado do Amazonas - UEA, na disciplina de Gestão Estratégica entre os anos de 2019 e 2021. Os resultados indicaram que é possível utilizar um modelo das 5 Forças de Porter com adaptações relacionas as características de uma organização do setor público. Nos resultados, também são propostas, para cada uma das forças, estratégias genéricas que podem ser utilizadas na busca da superação dos desafios apontados na utilização do modelo. O presente estudo apresenta uma ferramenta de aplicação prática de análise estratégica para o setor público, considerando que a grande maioria das publicações a respeito de tema gestão estratégica serem relacionados à experimentos realizados no setor privado.

Palavras-chave: Gestão Pública, Cinco Forças Competitivas de Porter, Gestão Estratégica.

\section{ABSTRACT}

This article aimed to propose an adaptation of Porter's 5 Forces tool to be used in the analysis of the external environment of a public organization and to propose lines of action that aim to overcome the identified strategic challenges. To carry out the study, the compilation of works carried out with Postgraduate students in Public Management at the Universidade do Estado do Amazonas - UEA, in the discipline of Strategic Management between the years 2019 and 2021. The results indicated that it is possible to use a model of Porter's 5 Forces with adaptations related to the characteristics of a public sector organization. In the results, generic strategies are also proposed for each of the forces that can be used in the search for overcoming the challenges identified in the use of the model. The present study presents a tool for the practical application of strategic analysis for the public sector, considering that the vast majority of publications on the topic of strategic 
management are related to experiments carried out in the private sector.

Keywords: Public Management, Porter's Five Competitive Forces, Strategic Management.

\section{INTRODUÇÃO}

Planejar a estratégia em uma organização pública, assim como em uma organização privada, é de fundamental importância para e realização de resultados sustentáveis no longo prazo. Tanto na organização pública, como na privada, o processo de planejamento estratégico passa por etapas como a elaboração de uma declaração de uma missão e valores organizacionais, discussão sobre a visão de longo prazo, realização de uma análise do ambiente no qual a essa organização está inserida e finalmente a proposição de ações que irão viabilizar o alcance da visão organizacional.

A estratégia é o meio pelo qual é possível o alcance da visão, que é hipótese de sucesso sustentável de logo prazo de uma organização e, por isso, precisa ser tratada e entendida para que posteriormente possa ser implementada. É inquestionável que o domínio da estratégia é importante tanto nas organizações públicas como privadas (COOPER, 2012).

Quando verificada as ferramentas de análise da estratégia disponíveis na literatura especializada, identifica-se menor ênfase em modelos que abordem a análise do ambiente de organizações públicas. Dentre as etapas de um planejamento estratégico, a que distancia mais a organização pública da privada é a realização da análise ambiental, mais especificamente a análise do ambiente externo da organização. Parte disso se deve ao fato da organização do setor privado estar inserida em um ambiente externo onde um dos fatores decisivos para o sucesso da estratégia é a análise das forças competitivas de seu segmento, enquanto na organização do setor público, apesar de possuir diversos desafios, não possui foco na concorrência e obtenção de lucro (DE ARAÚJO E SILVA, FLÁVIA; GONÇALVES, 2011).

A utilização da gestão estratégica no setor público é parte de um movimento global e giram em torno da necessidade de uma abordagem de gestão que faça frente à regulação política, que acaba limitando a capacidade da inovação no setor público. O caminho perseguido para superar a questão tem sido definição de 
metas de longo prazo e gestão proativa, em oposição à natureza supostamente reativa e de curto prazo da práticas tradicionais de gestão pública (MODELL, 2012).

A adoção de técnicas do setor privado, presumivelmente, fomentando a gestão de longo prazo, por exemplo, planejamento estratégico, tem sido um dos caminhos seguidos pelas organizações do setor público, porém, a área pública faz parte de um ambiente sujeito à normas presentes em leis e decretos, que precisam de movimentos políticos para serem alteradas. A administração pública possui muitas dificuldades em resolver com rapidez problemas da comunidade e dessa maneira, utilizar ferramentas de gestão da mesma forma que são utilizadas em organizações privadas, pode gerar resultados distintos do que foi planejado (MOTTA, 2013).

Os benefícios do planejamento estratégico no setor público têm sido identificados em diversos estudos, ao mesmo tempo em que a ausência de processos formais de formação de estratégia tende a prejudicar o desempenho das organizações públicas, sugerindo que os processos estratégicos fazem a diferença no desempenho das organizações públicas (ANDREWS et al., 2009).

Quando verificadas as mais tradicionais ferramentas de análise estratégica, as 5 Forças de Porter estão sempre entre as mais utilizadas, uma vez que permitem uma visão ampla do ambiente competitivo da indústria, permitindo a investigação das ameaças representadas pela rivalidade competitiva, compradores poderosos, fornecedores poderosos, novos entrantes em potencial e produtos substitutos (DOBBS, 2014). A vantagem de utilizar a análise das 5 Forças de Porter é o fato de possibilitar entender como essas forças podem limitar ou potenciar a lucratividade de determinado setor.

Este artigo tem como objetivo propor uma adaptação da ferramenta das 5 Forças de Porter para ser usada na análise do ambiente externo de uma organização pública, buscando manter similaridade com o conceito original da proposição de Porter e, também, propor linhas de ações que visem superar os desafios estratégicos identificados.

A pesquisa foi realizada com alunos de Pós-graduação em Gestão Pública da Universidade do Estado do Amazonas - UEA, na disciplina de Gestão Estratégica entre os anos de 2019 e 2021. Durante o desenvolvimento da 
disciplina Gestão Estratégica, foi solicitado aos alunos desenvolverem uma proposta de planejamento estratégico de uma organização pública, de preferência, onde pelo menos um dos integrantes dos grupos trabalhasse. Para elaboração do planejamento estratégico era apresentado o modelo tradicional das 5 Forças de Porter e solicitado aos alunos adaptarem esse modelo para a realidade que eles vivenciavam na administração pública, propondo ao final do trabalho, ações estratégicas para potencializar os resultados das organizações.

\section{AS 5 FORÇAS DE PORTER}

Porter (1986) sugere que as organizações devem levar em consideração a abordagem de três tipos de estratégia, que podem ser utilizadas de forma isolada ou mesmo combinada. $\mathrm{O}$ autor chamou essas três abordagens de estratégias genéricas, que são:

a) Liderança no custo total - consiste em reduzir os custos de produção por meio do ganho de escala e controle rígido de despesas operacionais. A redução de custos permite que a empresa enfrente melhor as cinco forças competitivas, pois ela só começaria a ter problemas logo após o concorrente mais eficiente passar a ter dificuldades em relação à uma das cinco forças, além do que os concorrentes menos eficientes já teriam sofrido antes as pressões competitivas;

b) Diferenciação - é a estratégia que busca uma posição única para a empresa, com a oferta de um produto ou serviço que não é encontrado nos concorrentes. A diferenciação permite a empresa trabalhar com margens de lucro altas, mesmo que para isso seja preciso renunciar a uma parte da participação de mercado;

c) Enfoque - baseia-se na escolha de uma determinada parcela do mercado que a empresa irá trabalhar suas ofertas. O enfoque pode ser dado tanto com relação a um segmento de mercado como em relação a uma área geográfica. A decisão pelo enfoque deve ser determinada quando a empresa percebe que ela é mais eficiente quando busca atender um alvo restrito ao invés de buscar o mercado de forma ampla como nas estratégias de liderança por custos e diferenciação.

Em seu artigo intitulado How Competitive Forces Shape Strategy (Como as 
Forças Competitivas Moldam a Estratégia), Michael Porter procurou analisar a competição entre empresas e entender a influência de cinco forças competitivas no ambiente organizacional, possibilita a definição de ações estratégica consistentes, uma vez que essas cinco forças exercem pressão, em maior ou menor grau, sobre uma empresa em determinado setor de mercado (PORTER, MICHAEL E., 1989).

Não somente a rivalidade entre as empresas, mas também era preciso entender o poder de negociação dos clientes e fornecedores, a pressão de produtos substitutos e a possibilidade de entrada de novos concorrentes no mercado. A partir da compreensão da atuação dessas forças em um mercado específico, seria possível estabelecer estratégias que proporcionassem a vantagem competitiva e o retorno em longo prazo sobre o capital (DREHEM; VANANY, 2020).

Quando Michael Porter concebeu o modelo das cinco forças competitivas, ele impulsionou a gestão estratégica para o cerne da agenda de gestão. A estrutura tornou-se uma peça central de textos sobre estratégia de negócios e gestão estratégica, e material essencial para exames de MBA e cursos similares em todo o mundo (GRUNDY, 2006).

Porter (1986) aprofunda a discussão sobre as Forças Competitivas, que se consagram então coma as Cinco Forças Competitivas de Porter, analisando a estratégia no contexto de indústrias, no qual as empresas que possuem produtos iguais ou similares devem buscar formas de diferenciação para sustentar suas estratégias. Na busca da diferenciação, as empresas precisam avaliar o seu posicionamento de forma sistematizada para poder definir então, quais devem ser suas ações estratégicas. $O$ autor enumera cinco forças competitivas (Figura 1) que interferem no posicionamento e podem fazer a diferença na disputa pelo mercado de clientes. 


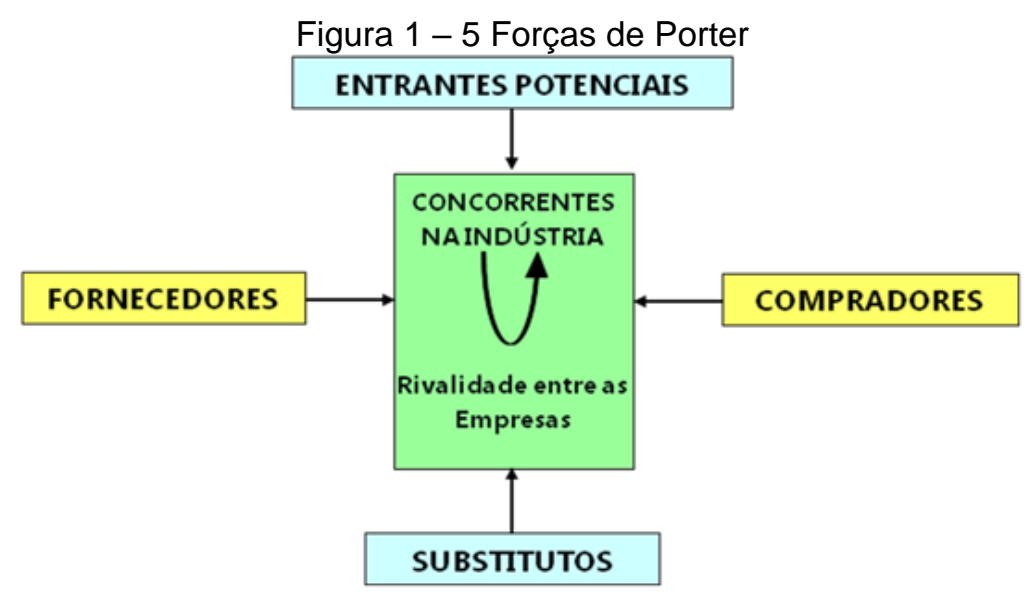

Fonte: Porter (1986)

A análise ambiental a partir das 5 Forças de Porter deve ser realizada de forma a avaliar a influência de cada uma delas em relação ao desempenho estratégico desejado pela organização, considerando as seguintes características de cada uma delas:

a) Ameaça dos novos entrantes - A entrada de novos concorrentes em um mercado altera as condições de negócio já existentes, pois esse novo entrante disputará clientes com os atuais participantes do mercado. De forma geral, essa nova condição poderá trazer redução nos preços de produtos, aumento de custos e necessidade de investimento em marketing fazendo com que haja a diminuição da lucratividade do mercado como um todo. A ameaça de um novo concorrente depende da presença de barreiras à sua entrada e da reação das empresas já existentes. Se as barreiras são altas e a retaliação esperada para o novo entrante é alta, a ameaça à entrada é considerada baixa;

b) Ameaça de produtos ou serviços substitutos - A possibilidade de ter seus produtos ou serviços substituídos por outra solução que atendam as demandas dos clientes é uma ameaça constante que precisa ser considerada pelas organizações, uma vez que esses novos produtos podem evidenciar a ineficiência dos produtos ou serviços atuais;

c) Poder de barganha dos compradores - Os compradores influenciam o mercado ao forçar os preços para baixo, demandar maior qualidade ou mais serviços e, portanto, possuem a capacidade de acirrar a concorrência em um determinado mercado. O poder de cada grupo de compradores depende das características, do volume e da importância de suas compras em relação ao mercado total; 
d) Poder de barganha dos fornecedores - Os fornecedores podem exercer seu poder de barganha sobre os participantes do mercado ao ameaçar aumentar os preços ou reduzir a qualidade dos produtos e serviços comprados. Poderosos fornecedores de matérias-primas chave podem pressionar a lucratividade de um mercado que não está apto a repassar os aumentos no custo em seus próprios preços. As condições que tornam esses fornecedores poderosos são similares às que tornam os compradores fortes; e

e) Rivalidade entre os competidores - A rivalidade entre os competidores evidencia-se na disputa por posições táticas que envolvem preço, propaganda, introdução de novos produtos, aumento de serviços ao consumidor ou melhora nos programas de distribuição, com o objetivo de aumentar o market share da empresa, em um determinado mercado. Em tese o aumento da rivalidade gera concorrência de preços, deixando o mercado menos atraente.

A grande contribuição de Porter com o conceito das cinco forças competitivas é a ampliação do conceito de concorrência, obrigando as empresas a olharem além dos seus concorrentes diretos, no momento que forem elaborar suas estratégias. Aliado a isso, Porter (1986) emprega um sentido de urgência nessa análise competitiva ampliada, chegando a considerar a mesma como rivalidade ampliada.

\section{AS 5 FORÇAS DE PORTER ADAPTADAS À GESTÃO PÚBLICA}

Analisando os diversos trabalhos desenvolvidos pelos alunos de Pósgraduação em Gestão Pública da Universidade do Estado do Amazonas - UEA, na disciplina de Gestão Estratégica entre os anos de 2019 e 2021, foi possível consolidar os resultados dos planejamentos propostos em um modelo adaptado do conceito das 5 Forças de Porter para a utilização em uma organização pública. As 5 Forças de Porter Adaptadas à Gestão Pública, permitem analisar o posicionamento estratégico de uma organização, verificando as demandas de ações estratégicas, a fim de que os propósitos de longo prazo dessa organização sejam atingidos

No Quadro 1 é apresentada a correlação das 5 Forças de Porter e a adaptação proposta para o setor público. 
Quadro 1 - Correlação das 5 Forças de Porter e a adaptação ao setor público

\begin{tabular}{|c|c|}
\hline $\mathbf{5}$ Forças de Porter & $\begin{array}{c}\mathbf{5} \text { Forças de Porter Adaptadas à } \\
\text { Gestão Pública }\end{array}$ \\
\hline Ameaça dos novos entrantes & Descontinuidade política \\
\hline $\begin{array}{c}\text { Ameaça de produtos ou serviços } \\
\text { substitutos }\end{array}$ & Excesso de burocracia \\
\hline $\begin{array}{c}\text { Poder de barganha dos } \\
\text { compradores }\end{array}$ & $\begin{array}{c}\text { Diversidade das Demandas da } \\
\text { Sociedade }\end{array}$ \\
\hline $\begin{array}{c}\text { Poder de barganha dos } \\
\text { fornecedores }\end{array}$ & $\begin{array}{c}\text { Poder de barganha dos } \\
\text { fornecedores }\end{array}$ \\
\hline Rivalidade entre os competidores & Interesse político \\
\hline
\end{tabular}

Fonte: Autor

Na Figura 2 é apresentada a proposta das 5 Forças de Porter Adaptadas à Gestão Pública, em uma analogia ao modelo tradicional de Porter.

Figura $2-5$ forças de porter adaptadas à gestão pública

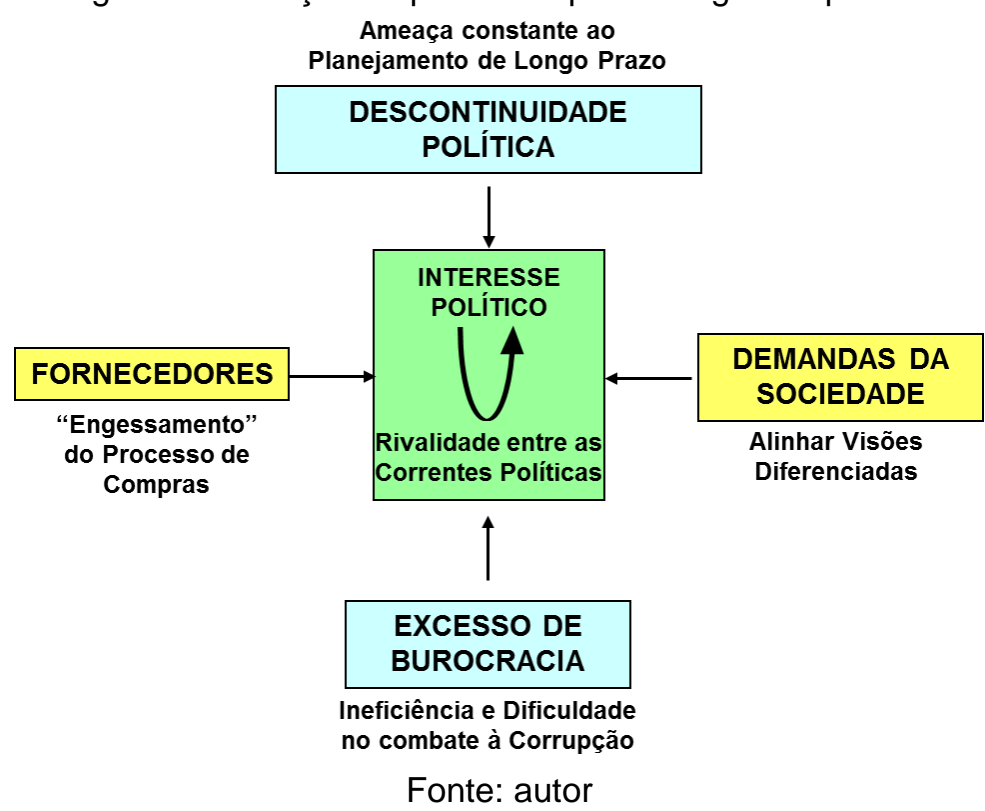

Em seguidas são apresentadas as características que devem ser consideradas na análise estratégica de cada uma das 5 Forças de Poter Adaptadas à Gestão Pública, além da relação entre o modelo proposto e o modelo tradicional:

a) Descontinuidade política - Em substituição a ameaça dos novos entrantes, a descontinuidade política, com a possibilidade de alterações de governos a cada 4 (quatro) anos, pode ser considerada como a entrada de atores importantes que podem interferir no planejamento de longo prazo, gerando, por vezes, mudanças de rumos em projetos estratégicos antes que eles apresentem 
os resultados previstos, ou até mesmo criando um ambiente onde se priorizem projetos de curto prazo, pela convicção de que o mesmo será finalizado é bem maior;

b) Excesso de burocracia - Em substituição a ameaça de produtos ou serviços substitutos, foi possível identificar o excesso de burocracia como um fator gerador de ineficiências sistêmicas e, também, mais um entrave no combate à corrupção. No modelo original de Porter, os produtos substitutos se transformam em uma ameaça por conta de evidenciarem a ineficiência dos produtos que estão sendo substituídos. Comparativamente, o excesso de burocracia atua como forma de gerar ineficiência nos processos dos órgãos públicos. Nesse caso, é necessário destacar que está sendo tratado do excesso e disfunção da burocracia, considerando que essa ferramenta, quando utilizada de forma adequada e equilibrada, provê excelentes resultados para a organização;

c) Diversidade das Demandas da Sociedade - Em substituição ao poder de barganha dos compradores, foi verificado que a diversidade das demandas da sociedade se torna um desafio estratégico importante para a gestão pública, uma vez que cada segmento da sociedade possui um tipo de demanda diferente para ser atendida pelo estado. Priorizar e alinhar essas demandas é um grande desafio para o gestor público e por esse motivo deve ser considerado na estratégia da organização;

d) Poder de barganha dos fornecedores - Nesse caso, a força se mantém como poder de barganha dos fornecedores, porém além de todas as questões já levantadas por Porter sobre esse assunto, as organizações públicas ainda possuem como agravante o fato de estarem sujeitas a legislações restritivas com relação seus processos de aquisições, podendo gerar, em certos casos, o engessamento da gestão pública; e

e) Interesse político - Em substituição rivalidade entre os competidores é possível verificar que o interesse político faz o papel de grupos de interesse que buscam resultados políticos em função do poder de influência que exercem, em determinado órgão. A sustentação da governabilidade pode fazer com que a gestão pública demande apoio de correntes partidárias diversas, que em contrapartida exigem participação em decisões sobre questões relevantes e até mesmo exigem participação formal na estrutura de governo. 
Como estratégias sugeridas para reduzir as ameaças e ao mesmo obter uma vantagem competitiva em relação a cada uma das 5 Forças de Porter Adaptadas à Gestão Pública, é possível destacar (Quadro 2): 
Quadro 2: Estratégias sugeridas para as 5 Forças de Porter Adaptadas à Gestão Pública

\section{Forças de Porter}

Adaptadas à Gestão Pública

\begin{tabular}{|c|c|}
\hline $\begin{array}{l}\text { Descontinuidade } \\
\text { política }\end{array}$ & $\begin{array}{l}\text { Basear as ações do órgão em fundamentação técnica; } \\
\text { Garantir a excelência nos serviços desenvolvidos pelo } \\
\quad \text { órgão; } \\
\text { Buscar a formação de quadro com funcionários } \\
\text { estatutários; } \\
\text { Viabilizar um plano de cargos e salários que possam atrair } \\
\text { profissionais competentes. }\end{array}$ \\
\hline Excesso de burocracia & $\begin{array}{l}\text { Utilizar técnicas de definição de cadeia de valor e } \\
\text { mapeamento de processos; } \\
\text { Utilizar ferramentas da gestão da qualidade (indicadores de } \\
\text { performance de processos); } \\
\text { Disseminar a cultura de foco nos fins (resultados) } \\
\text { resultados e não nos meios (burocracia). }\end{array}$ \\
\hline $\begin{array}{l}\text { Diversidade } \\
\text { das Demandas da } \\
\text { Sociedade }\end{array}$ & $\begin{array}{c}\text { Utilizar meios de consulta a sociedade sobre a priorização } \\
\text { de demandas por políticas públicas; } \\
\text { Comunicar as políticas públicas em andamento e as que } \\
\text { estão concluídas; } \\
\text { Identificar a possibilidade de integração de projetos } \\
\text { isolados em programas, visando uma coordenação mais } \\
\text { abrangente das ações. }\end{array}$ \\
\hline $\begin{array}{l}\text { Poder de } \\
\text { barganha dos } \\
\text { fornecedores }\end{array}$ & $\begin{array}{c}\text { Criar garantias de pagamento aos fornecedores } \\
\text { Viabilizar a aquisição em escala } \\
\text { Parcerias com os fornecedores; } \\
\text { Treinamentos para a cadeia de suprimento; } \\
\text { Conhecimento dos métodos e custos dos fornecedores; }\end{array}$ \\
\hline $\begin{array}{l}\text { Interesse } \\
\text { político }\end{array}$ & $\begin{array}{l}\text { Buscar a formação de quadro com funcionários } \\
\quad \text { estatutários; } \\
\text { Viabilizar um plano de cargos e salários que possam atrair } \\
\text { profissionais competentes; } \\
\text { Privilegiar a indicação de funcionários do quadro para os } \\
\text { cargos chaves. }\end{array}$ \\
\hline
\end{tabular}

Fonte: autor

\section{Estratégia sugerida}

Basear as ações do órgão em fundamentação técnica; ia nos serviços desenvolvidos pelo ação de quadro com funcionários 
burocracia; c) Diversidade das demandas da Sociedade; d) Poder de barganha dos fornecedores; e e) Interesse político.

Para cada uma das forças propostas para o setor público, foram apresentadas estratégias genéricas que podem ser utilizadas na busca da superação dos desafios apontados nas 5 Forças de Porter Adaptados à Gestão Pública.

Como contribuição, o presente estudo apresenta uma ferramenta de aplicação prática de análise estratégica para o setor público, considerando que a grande maioria das publicações a respeito de tema gestão estratégica serem relacionados à experimentos realizados no setor privado.

Como sugestão para a continuação da pesquisa, sugere-se a realização de estudos qualitativos que procurem aprofundar a efetividade da utilização do modelo proposto, a fim de no futuro, obter-se-á um parâmetro onde verifique-se o impacto tanto da análise das 5 Forças de Porter Adaptadas à Gestão Pública, quanto das estratégias sugeridas a partir desta análise. 


\section{REFERÊNCIAS}

Andrews, rhys et al. Strategy formulation, strategy content and performance: an empirical analysis. Public management review, v. 11, n. 1, p. 1-22, 2009.

Cooper, robert k. Strategy \& leadership article information : 2012.

De araújo e silva, flávia; gonçalves, carlos alberto. O processo de formulação e implementação de planejamento estratégico em instituições do setor público. Revista de administração da universidade federal de santa maria, v. 4, n. 3, p. 458-476, 2011.

Dobbs, michael e. Guidelines for applying porter's five forces framework: a set of industry analysis templates. Competitiveness review, v. 24, n. 1, p. 32-45, 2014. Drehem, bassam muhammad; vanany, iwan. Strategic analysis on start-up business using objectives and key results method in rumah kapas holding. N. 3, 2020.

Grundy, tony. Rethinking and reinventing michael porter's five forces model. Strategic change, v. 15, n. 5, p. 213-229, 2006.

Modell, sven. Strategy, political regulation and management control in the public sector: institutional and critical perspectives. Management accounting research, $\mathrm{h}$ index 76citações 71, v. 23, n. 4, p. 278-295, 2012. Disponível em: <http://dx.doi.org/10.1016/j.mar.2012.05.001>.

Motta, paulo roberto de mendonça. O estado da arte da gestão pública. Revista de administração de empresas, v. 53, n. 1, p. 82-90, 2013.

Porter, michael. Estratégia competitiva: técnicas e análise de indústria e da concorrência. Rio de janeiro: [s.n.], 1986.

Porter, michael e. How competitive forces shape strategy. Readings in strategic management, p. 133-143, 1989. 